\title{
DISCUSSION.
}

\section{THE MECHANISM OF IMITATION.}

The object of this paper is to explain the psycho-physical process by which acts of imitation are performed. We often hear imitation spoken of as an instinct, and of course, in the loose popular sense of the term, there may be no objection to speaking of the tendency to imitate as instinctive in mankind. But if we use the term instinct in a technical sense as applying to those acts which are made possible by hereditary paths of discharge in the nervous system, it seems impossible to bring our acts of imitation under this head. We can understand how a definite reflex might become hereditary. The act of swallowing when something is placed in the mouth, is a perfectly definite sensori-motor reflex, and we can easily conceive that the nerve arrangement necessary for this act should be prenatally established. But in the case of imitation we have no single definite act, but an indefinite variety of actions. No one definite set of nerve adjustments could explain such different activities as the imitation of sound, the imitation of a movement of the hand, and an imitation of the shake of the head. The very use of the single term imitation for such a large variety of actions, has a tendency to mislead. Many writers speak of imitation as if it were a sort of faculty, and this leads to the usual error of faculty psychology - the individual act is thought to be sufficiently explained when it is shown to be an instance of the general activity of the faculty. As James says there is no such thing as memory, but only memories, so we might say there is no such thing as imitation, but only imitative actions.

Our instincts are sensi-motor, our imitations ideo-motor. Since our ideas are not hereditary, but are always individual acquisitions, it seems necessary to regard the actions especially associated with these acquired ideas as also acquired. A movement which depends upon the perception of another's doings cannot be more original than the act of perception itself. In speaking of perception, Professor James says, "Nature is frugal in her operations, and will not be at the expense of a particular instinct to give us that knowledge which experience and habit will soon produce. Every perception," he says, "is an acquired perception." 1 Now this, it seems to me, applies to imita-

1 Principles of Psychology, Vol. II., p. 78. 
tion as well as to perception. Nature does not furnish us with particular instincts to give us those actions which experience and habit will soon produce. Every imitation is, I believe, an acquired imitation.

Many recent writers seem, however, to regard imitation as hereditary and instinctive. Thus Professor James himself includes imitation in his enumeration of the prominent instincts of man. ${ }^{1}$ Yet he shows an apprehension of something other here than a single instinct by distinguishing ' the instinct to imitate sounds,' from 'the instinct to imitate gestures.' Had he carried this differentiation further he would soon have seen that the great variety of imitative acts precludes all thought of their reference to one or two hereditary instincts. Royce, in his recent Outlines of Psychology, speaks of the sources of the social interest, as instinctive and hereditary, and then goes on to say, "On the basis of the general social interests there appear more special instuncts amongst which the most prominent is the complex of instincts suggested by the name imitation." " Tarde, in his Laws of Imitation, calls imitation the 'action at a distance of one brain upon another.'s He speaks of ' a will to imitate' as being handed down,' and he quotes from Maudsley with apparent approval the statement, "It cannot be too clearly apprehended that there is a sort of innate tendency to mimicry in the nervous system." " Baldwin's view is not entirely clear to me. He seems to regard imitation as an acquisition of the race, but as an instinct in the individual. At any rate he speaks of the 'imitative instinct,' and again refers to 'the instinct to imitate' as found in the child and in animals. ${ }^{6}$

In contrast with these writers who more or less definitely pronounce imitation an instinct, we may note this statement of Stout in his just published work, The Groundwork of Psychology. "Both spontaneous and deliberate imitation," he says, "presupposes a motor association between the perception or idea of the act to be imitated, and more or less similar movements which the child has already learned to perform." " Stout, it seems to me, is on the right track. He does not explain, however, the way in which these motor associations first arise. These motor associations, it seems to me, may be explained as follows: In same cases they are based on instinct. The

IIbid., p. 408.

2P. 275.

'G. Tarde, Laws of Imitatson, trans. p. 199.

- Ibid., p. 193.

5 Tbid., p. 88.

${ }^{6}$ Baldwin, Mental Development, p. 290.

?P. 82 . 
child instinctively cries at its own pain, and thus associates the sound of the cry with the cry movements. This association established, it becomes then perfectly natural, on the principle of ideo-motor action, for the child to cry when he hears another cry. In other cases the association between the idea and the movement may have been established by purely random activities. The spontaneous overflow of nervous energy makes the child wave his hands - he then sees the hand movement, and thus establishes a path of connection between the ideational process and the corresponding motor process. With this connection established, it is easy to understand how the child comes to wave his hand when he sees another perform the same act. In some cases probably the associations on which the imitative act depends may depend upon the imitations of others. Take the case of the imitative smile. The child cannot see his own smile and thus form a visual image of it, as he can of his hand movements. But the mother smiles when she sees the smiling face of the babe, and the child thus associates its own motor feelings of the smile with the visual idea of the smile as seen reflected in its mother's face. The necessary association is now established, and thereafter the child readily smiles when he sees others smile. In the case of vocal sounds while the imitation of the child by others may not be an absolutely indispensable factor, it is yet of great service in establishing the motor associations. To hear its own sound uttered by another, calls attention to it, makes its auditory image more definite and vivid and thus associates it more firmly with the movements of articulation. By means then of his original instinctive reflexes, his random movements, and the imitations of his movements, which he sees made by others, the child forms a sufficient fund of motor associations to explain his imitative acts, without the need of assuming any special instinct, endowment or faculty of imitation. Thus far we have considered only the first simple imitations of the child. But if these are not instinctive certainly none are. The more elaborate and complex imitations of later life are simply combinations and coördinations of the elemental movements already learned. As imagination can create nothing for which the ideational experience of the past does not supply material, so imitation can perform no act for which earlier motor experience does not furnish the elements.

Closely connected with imitation is sympathy. This connection is illustrated by an instance of my own son's babyhood. Whenever we repeated to him the nursery ditty - 'This little pig goes to market,' etc., he would always break out crying when we said the last line - 
'This little pig cried Wee, Wee, Wee! I can't find my way home.' The 'wee, wee, wee'uttered in a somewhat pathetic tone of voice produced a cry which was certainly imitative, and perhaps in some measure sympathetic. One other example may be given - an incident related to me by a friend of his little two-ycar-old daughter. One day as the father was holding the child in his arms playing with her, she got quite a hard bump against his forehead and began to cry. To distract her attention, he took her hand, patted his forehead with it, and said, 'poor papa, poor papa!' The next day the child got a bump against a chair, and her father was much surprised to see her pat the chair and hear her say ' poor chair!' Certainly no one would claim that we inherit an instinct to sympathize with injured chairs and I believe there is as little ground for making sympathy an instinct in any case.

James again counts sympathy among the instincts,' and Baldwin regards organic sympathy as instinctive. ${ }^{2}$ But much the same diffculties arise when we try to think how the vast variety of our sympathies can be accounted for by an inherited nervous mechanism as in the case of our imitations. In order to explain the first sympathetic feelings we need only to add to imitation the James-Lange theory of emotions. As already explained, the child cries when he hears another cry. He sees another in an attitude of pain or grief and imitatively assumes that attitude, but the assumption of the attitude excites the corresponding emotion and the child thus acquires the sympathetic feeling. But even if we do not accept the theory that the 'expression' makes the emotion, it is still unnecessary to regard sympathetic feelings as instinctive. The child does not feel the woes and joys of others until he has already experienced at least elemental feelings of the same sort in his own person. Having established then a certain fund of association between feelings and their outward expression, the imitation of the expression of feeling that he sees in others will awaken the kindred emotions in his own breast.

One objection to this experiential theory of imitation should be considered. It seems to be the social psychologists, and those who have approached the subject from the sociological side, who are especially inclined to regard imitation as an instinct, an endowment, or a quasi-faculty. When we think of the tremendous rôle which imitation plays in the development and education of the individual and in the entire organization and structure of society, can we regard it as any-

'Principles of Psychology, Vol. II., p. 410.

\& Social and Ethical Interpretations, p. 222. 
thing less than a native endowment? Or, to put the question more concretely, if imitation is only one type of ideo-motor action, why should it acquire such a preponderant influence? Why should the ideas enacted before us in the doings of our fellows take precedence in their influence on conduct over the numberless ideas of all sorts that crowd the mind? In answering this question we may note first that when a number of motor ideas are in the mind it is the one which is most interesting, the one which is most vividly apprehended, or which most forcibly strikes the attention, that is sure to be executed. From the first experience of parental care, to the last days of life, our social relations are of the utmost importance to us. There is therefore a constant and accumulative development of social interests. Where our interest is there our attention is. The child might wave its arms in imitation of the waving branches of a tree were it as interested in the tree as in the movements of its parents, brothers and sisters. Then too the movements actually enacted are much more clearly and vividly apprehended than those that are suggested by mere words or ideas that arise in mind. In fact many activities that can readily be understood when seen, can hardly be described at all. The gymnasium instructor may be quite unable to tell in words how he performs a certain feat, but by performing the feat in the sight of his pupils, they get a far clearer apprehension of it than words can possibly give. Moreover the very infertility of our minds as to ideas of conduct, makes us prone to follow the examples presented before us. We are endowed with a store of energy, we are bound to act, and given the proper motor associations the doings depicted before us offer the line of least resistance to our conduct. Lack of originality is as manifest in actions as in ideas, and it is therefore not to be wondered at that the doings made vivid by the acts of others, and enforced by the growing power of our social interests should have a dominant influence on our conduct. There is nothing then, it seems to me, in the importance of the rôle which imitation plays in individual and social life to invalidate this simple experiential theory of its workings.

F. C. FreNCH.

UNIVARSITY OF NERRASKA. 